\title{
The roles of sulfuric acid in new particle formation and growth in the mega-city of Beijing
}

\author{
D. L. Yue ${ }^{1}$, M. Hu ${ }^{1}$, R. Y. Zhang ${ }^{1,2}$, Z. B. Wang ${ }^{1}$, J. Zheng ${ }^{2}$, Z. J. Wu ${ }^{1,3}$, A. Wiedensohler ${ }^{3}$, L. Y. He ${ }^{4}$, X. F. Huang ${ }^{4}$, \\ and T. Zhu ${ }^{1}$ \\ ${ }^{1}$ State Key Joint Laboratory of Environmental Simulation and Pollution Control, College of Environmental Sciences and \\ Engineering, Peking University, Beijing 100871, China \\ ${ }^{2}$ Department of Atmospheric Science, Texas A\&M University, College Station, Texas 77843, USA \\ ${ }^{3}$ Leibniz Institute for Tropospheric Research, Permoserstrasse 15, Leipzig 04318, Germany \\ ${ }^{4}$ Key Laboratory for Urban Habitat Environmental Science and Technology, Shenzhen Graduate School of Peking University, \\ Shenzhen 518055, China
}

Received: 15 December 2009 - Published in Atmos. Chem. Phys. Discuss.: 3 February 2010

Revised: 26 May 2010 - Accepted: 26 May 2010 - Published: 28 May 2010

\begin{abstract}
Simultaneous measurements of gaseous sulfuric acid and particle number size distributions were performed to investigate aerosol nucleation and growth during CAREBeijing-2008. The analysis of the measured aerosols and sulfuric acid with an aerosol dynamic model shows the dominant role of sulfuric acid in new particle formation (NPF) process but also in the subsequent growth in Beijing. Based on the data of twelve NPF events, the average formation rates $\left(2-13 \mathrm{~cm}^{-3} \mathrm{~s}^{-1}\right)$ show a linear correlation with the sulfuric acid concentrations $\left(R^{2}=0.85\right)$. Coagulation seems to play a significant role in reducing the number concentration of nucleation mode particles with the ratio of the coagulation loss to formation rate being $0.41 \pm 0.16$. The apparent growth rates vary from 3 to $11 \mathrm{~nm} \mathrm{~h}^{-1}$. Condensation of sulfuric acid and its subsequent neutralization by ammonia and coagulation contribute to the apparent particle growth on average $45 \pm 18 \%$ and $34 \pm 17 \%$, respectively. The $30 \%$ higher concentration of sulfate than organic compounds in particles during the seven sulfur-rich NPF events but $20 \%$ lower concentration of sulfate during the five sulfur-poor type suggest that organic compounds are an important contributor to the growth of the freshly nucleated particles, especially during the sulfur-poor cases.
\end{abstract}

Correspondence to: $\mathrm{M} . \mathrm{Hu}$

(minhu@pku.edu.cn)

\section{Introduction}

Atmospheric aerosols influence climate through affecting the radiative budget of the atmosphere and acting as cloud condensation nuclei, negatively impact human health, and degrade visibility. New particle formation (NPF), one of the important sources of ambient aerosols, is frequently observed worldwide (Kulmala et al., 2004; Kulmala and Kerminen, 2008). NPF is characterized by a sharp increase in number concentrations of nucleation mode particles and subsequent growth of freshly nucleated particles. Atmospheric measurements show that new particle formation rates, defined for $3 \mathrm{~nm}$ particles, typically vary from 1 to $70 \mathrm{~cm}^{-3} \mathrm{~s}^{-1}$; the growth rate of freshly nucleated particles has been measured in the range of 1-20 $\mathrm{nm} \mathrm{h}^{-1}$ (Kulmala et al., 2004), with the higher values observed during summertime (Wu et al., 2007). However, the species that participate in the nucleation process and subsequent growth are presently not known for certain. Atmospheric observations and laboratory experiments suggest that sulfuric acid often plays a dominant role (Birmili et al., 2003; Boy et al., 2005), but other species, such as organic compounds, have also been speculated to be important in new particle formation and growth (O'Dowd et al., 2002; Zhang et al., 2004; Barsanti et al., 2009). Coagulation is also important for NPF events, reducing nucleation mode particle number concentrations but leading to particle growth (Kerminen and Kumala, 2002). A few investigations about NPF events have been done in China, but all of them only reported some parameters such as the occurrence frequency,

Published by Copernicus Publications on behalf of the European Geosciences Union. 
formation rate, and growth rate of NPF events (Wu et al., 2007; Lin et al., 2007; Liu et al., 2008; Yue et al., 2009). The precursors, such as sulfuric acid, and the role of coagulation for new particle formation and growth have not been studied in detail.

In this paper, we report simultaneous measurements of particle number size distributions from 3 to $900 \mathrm{~nm}$ and concentrations of gaseous sulfuric acid to investigate aerosol nucleation and growth during the Campaign of Atmospheric Research in Beijing and Surrounding Areas in the summer of 2008 (CAREBeijing-2008). An analysis of the measured aerosols and sulfuric acid with an aerosol dynamic model is performed to identify the species responsible for new particle formation and growth. The formation rates and apparent growth rates of freshly nucleated particles are estimated, and the roles of intramodal coagulation among nucleation mode particles (i.e. self-coagulation) and extramodal coagulation between the nucleation mode particles and preexisting particles (i.e. intermodal coagulation) are assessed.

\section{Methodology}

\subsection{Experimental method}

Regional NPF events were observed by a twin differential mobility particle sizer (TDMPS) on the roof of a building (about $15 \mathrm{~m}$ above the ground level) on the campus of Peking University (PKU), which is located in the northwestern urban area of Beijing, outside the fourth-ring road, from 12 July to 25 September during CAREBeijing-2008. There were twelve regional NPF events during the measurement period. Simultaneous measurements of gaseous sulfuric acid were performed by an atmospheric pressure-ion drift-chemical ionization mass spectrometer (AP-ID-CIMS).

The TDMPS measured the particle number size distributions from 3 to $900 \mathrm{~nm}$ (Stokes diameter) with a time resolution of $10 \mathrm{~min}$. It consisted of two Hauke-type differential mobility analyzers and two condensation particle counters (model 3010 and model 3025, TSI Inc., St. Paul, MN, USA), as previously described by Wu et al. (2007). The relative humidity within the whole system was kept below $30 \%$. Size-dependent losses due to diffusion within the inlet were corrected with empirical particle loss corrections as given by Willeke and Baron (1993).

The AP-ID-CIMS was developed at Texas A\&M University. Unlike a traditional AP-CIMS (Eisele and Tanner, 1993), AP-ID-CIMS utilized a special ion-drift tube (Fortner et al., 2004) capable of operating at one atmospheric pressure to confine and regulate the ion-molecular reaction between nitrate anions $\left(\mathrm{NO}_{3}^{-}\right.$) and gaseous $\mathrm{H}_{2} \mathrm{SO}_{4}$ (Arnold and Fabian, 1980) thus to achieve better detection precision. A detailed description of the AP-ID-CIMS methodology was introduced by Zheng et al. (2010a). Typically, ambient air was sampled at $1.2 \mathrm{~m}^{3} \mathrm{~min}^{-1}$ through a $30 \mathrm{~cm}$-long- $10 \mathrm{~cm}$ - diameter inlet to minimize wall loss. AP-ID-CIMS was continuously and sequentially monitoring both reagent and product ions. Each measurement cycle was about $12 \mathrm{~s}$. The corresponding detection limit was about $1.4 \times 10^{5} \mathrm{~cm}^{-3}$ based on three times of the standard deviation $(3 \sigma)$ of the baseline noise. Variation of the in-situ instrument response to primary $\mathrm{H}_{2} \mathrm{SO}_{4}$ standards was within $36 \%$ of the average value. The $\mathrm{H}_{2} \mathrm{SO}_{4}$ data used in this work was 10 min averaged to keep consistent with the TDMPS. More detailed information of $\mathrm{H}_{2} \mathrm{SO}_{4}$ observation during CAREBeijing-2008 was discussed in a companion paper of this special issue (Zheng et al., 2010b).

\subsection{Aerosol dynamic modeling}

For each particle number size distribution, the nucleation mode was fit with a lognormal distribution, characterized by the total mode number concentration, $N$, geometric mean diameter, $D_{\mathrm{g}}$, and geometric standard deviation, $\sigma_{\mathrm{g}}$. Least squares fit was performed with manually set limits and adjusted to capture the region around the peak of the distribution (Heintzenberg, 1994). The parameters $N, D_{\mathrm{g}}, \sigma_{\mathrm{g}}$ are time dependent, as nucleation mode particles grow and evolve.

The average formation rate (FR) is calculated from:

$\mathrm{FR}=\frac{d N}{d t}+F_{\text {coag }}+F_{\text {growth }}$

where $F_{\text {coag }}$ is the coagulation loss of nucleation mode particles (Eq. 2), and $F_{\text {growth }}$ is the flux of particles growing up to over $25 \mathrm{~nm}$.

$$
F_{\text {coag }}=\left(\sum_{\mathrm{i}} K_{\mathrm{i}} N_{\mathrm{i}}\right) \times N
$$

where $N_{\mathrm{i}}$ is the particle number concentration of the $i$-th bin and $K_{\mathrm{i}}$ is the Brownian coagulation coefficient between the nucleation mode and the $i$-th bin particles.

The apparent particle growth rate (GR) is expressed as (Heintzenberg, 1994):

$\mathrm{GR}=\frac{\Delta D_{\mathrm{g}}}{\Delta t}$

This apparent growth process is mainly caused by three mechanisms: intramodal coagulation, extramodal coagulation with larger preexisting particles, and vapor condensation.

When the concentration of photochemically produced gaseous sulfuric acid in the atmosphere is much greater than its saturation value (Marti et al., 1997), sulfuric acid is widely believed to participate in the nucleation process and its condensation will contribute to particle growth. As ammonia is abundant in the Beijing area (2-30 ppb), neutralization of sulfuric acid by ammonia is expected to occur readily to form ammonium sulfate. It is also supported by the ratio of sulfate to ammonium $\left(\left[\mathrm{SO}_{4}^{2-}\right] / 2\left[\mathrm{NH}_{4}^{+}\right]=1.1 \pm 0.4\right)$ in particles 
from 40 to $400 \mathrm{~nm}$ (corresponding to 60 to $600 \mathrm{~nm}$ in vacuum dynamic diameter with the assumed particle density of $1.5 \mathrm{~g} \mathrm{~cm}^{-3}$ ) determined by an Aerodyne aerosol mass spectrometer (AMS, detailed description about AMS in Huang et al., 2010). The rate of sulfuric acid condensation and neutralization process is limited by the condensation of sulfuric acid which can be modeled as coagulation between nucleation mode particles and $\mathrm{H}_{2} \mathrm{SO}_{4}$ molecules. Coagulation can scavenge the newly formed particles and also affect the apparent growth rate due to the high concentrations of particles produced by nucleation and the preexisting particles (Stolzenburg et al., 2005).

The time rates of change of the modal parameters due to these three mechanisms are approximated by assuming that the mode is in the free molecule regime and applying a firstorder transition regime correction (Stolzenburg et al., 2005). The time derivatives of the three modal parameters are obtained from the time derivatives of the zeroth, first and second moments $\left(M_{k}, k=0,1,2\right)$ in particle volume $\left(v=\pi D_{\mathrm{p}}^{3} / 6\right)$ of the mode where

$$
\begin{aligned}
M_{\mathrm{k}}(t) & \equiv \int_{\text {mode }} v^{k} n(v, t) d \ln v \\
& =N(t) \cdot D_{\mathrm{g}}^{3 k}(t) \cdot \exp \left[\frac{9}{2} k^{2} \ln ^{2} \sigma_{\mathrm{g}}(t)\right] \\
n(v, t) & \equiv \frac{d N}{d \ln v}=\frac{1}{3} \frac{d N}{d \ln D_{\mathrm{p}}}
\end{aligned}
$$

For intramodal coagulation, the time derivatives of the moments can be written as

$$
\begin{aligned}
& \frac{d M_{\mathrm{k}}}{d t}=\frac{1}{2} \int_{v_{2}} \int_{v_{1}}\left[\left(v_{1}+v_{2}\right)^{k}-v_{1}^{k}-v_{2}^{k}\right] \beta\left(v_{1}, v_{2}\right) n\left(v_{2}, t\right) \\
& n\left(v_{1}, t\right) d \ln v_{1} d \ln v_{2}
\end{aligned}
$$

where $\beta\left(v_{1}, v_{2}\right)$ is the Fuchs (1964) transition regime collision frequency function for particles of volumes $v_{1}$ and $v_{2}$ and both integrals are over the nucleation mode.

Extramodal coagulation depletes small particles in the nucleation mode more rapidly than larger ones, thereby shifting the modal size to larger particles and contributing to apparent growth. For extramodal coagulation the time derivatives of the moments can be written as

$$
\frac{d M_{\mathrm{k}}}{d t}=-\int_{v_{1}} \int_{v_{2}} v^{k} \beta\left(v_{1}, v_{2}\right) n\left(v_{1}, t\right) n\left(v_{2}, t\right) d \ln v_{2} d \ln v_{1}
$$

where the outer integral $\left(v_{1}\right)$ is over the nucleation mode and the inner integral $\left(v_{2}\right)$ is over the extramodal region above the nucleation mode.

The rate of sulfuric acid condensation and neutralization process is limited by the condensation of sulfuric acid which can be modeled as coagulation between nucleation mode par- ticles and $\mathrm{H}_{2} \mathrm{SO}_{4}$ molecules. So the time derivatives can be written as

$$
\frac{d M_{\mathrm{k}}}{d t}=N_{\mathrm{s}}(t) \int_{\mathrm{v}}\left[\left(v+v_{\mathrm{n}}\right)^{k}-v^{k}\right] \beta\left(v, v_{\mathrm{s}}\right) n(v, t) d \ln v
$$

where $v_{\mathrm{n}}$ and $v_{\mathrm{S}}$ are the respective volumes of $\left(\mathrm{NH}_{4}\right)_{2} \mathrm{SO}_{4}$ and $\mathrm{H}_{2} \mathrm{SO}_{4}$ molecules, $N_{\mathrm{s}}$ is the number concentration of $\mathrm{H}_{2} \mathrm{SO}_{4}$ molecules, where $\beta\left(v, v_{\mathrm{s}}\right)$ is the Fuchs (1964) transition regime collision frequency function for nucleation mode particles of volume $v$ and $\mathrm{H}_{2} \mathrm{SO}_{4}$ molecules of volume $v_{\mathrm{s}}$, and the integral is over the nucleation mode.

Intramodal and extramodal coagulation loss rates of the nucleation mode particles are also separately obtained from the Moment Method above.

Hygroscopic growth factors of the nucleation mode particles are obtained from Biskos et al. (2009), and those of larger particles are calculated from our earlier measurements (Wu et al., 2007).

\section{Results and discussion}

The NPF events have been observed at PKU with a frequency of $10-70 \%$ based on the long-term measurement since March 2004. The NPF events usually occur in conjunction with high speed wind from the north, low relative humidity (below 45\%), and intense solar radiation. A higher NPF frequency and larger formation rates were observed in spring, but a lower NPF frequency and higher growth rates were observed in summer (Wu et al., 2007).

For the twelve NPF events during CAREBeijing-2008, the average formation rates and apparent growth rates were determined in the ranges of $2-13 \mathrm{~cm}^{-3} \mathrm{~s}^{-1}$ and $3-11 \mathrm{~nm} \mathrm{~h}^{-1}$, respectively, which are within the corresponding ranges in the summer from 2004 to 2008 (i.e., $2-21 \mathrm{~cm}^{-3} \mathrm{~s}^{-1}$ and $0.3-$ $12 \mathrm{~nm} \mathrm{~h}^{-1}$, respectively). The present formation rates are lower than those of $20-70 \mathrm{~cm}^{-3} \mathrm{~s}^{-1}$ in Atlanta; the present growth rates are comparable to typical particle growth rates of 1-20 $\mathrm{nm} \mathrm{h}^{-1}$ (Kulmala et al., 2004).

\subsection{New particle formation}

NPF events occurred when the sulfuric acid concentration was relatively high, larger than about $5 \times 10^{6} \mathrm{~cm}^{-3}$, while the average sulfuric acid concentration for non-NPF days was about $2 \times 10^{6} \mathrm{~cm}^{-3}$. The sulfuric acid concentration necessary for NPF occurrence in Beijing is similar to that previously reported (McMurry et al., 2005). Figure 1 shows that the nucleation mode particle number concentration increases quite fast following the sharp increase of sulfuric acid concentration during NPF events. A linear correlation between the average sulfuric acid concentrations and average formation rates for each NPF event is showed in Fig. 2 $\left(R^{2}=0.85\right)$, indicating that sulfuric acid plays a dominant role in NPF in Beijing. It has been previously reported that the 


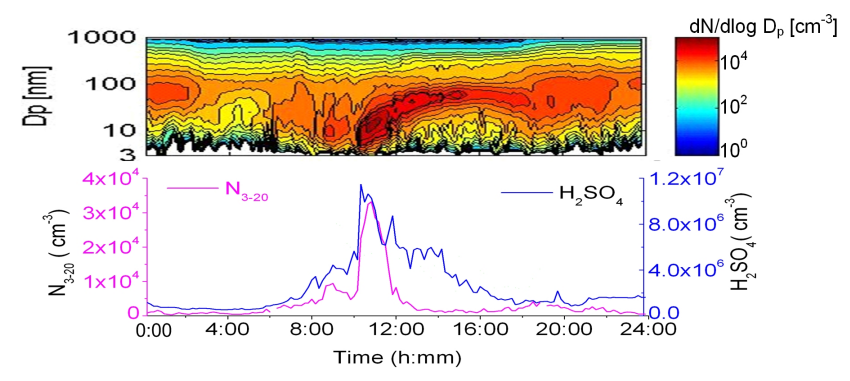

Fig. 1. Particle number size distributions, particle number concentrations (3-20 nm) and sulfuric acid concentrations on a NPF day, 12 August 2008 (Local Time).

mass size distributions of sulfate, ammonium, and oxalate shifted to smaller sizes on NPF event days compared with non-NPF event days (Yue et al., 2009) and NPF events may involve sulfuric acid, ammonia, and oxalic acid. During the CAREBeijing-2008 campaign, similar phenomena were also found for sulfate and ammonium in particles from 40 to $400 \mathrm{~nm}$.

The ratio of coagulation loss to formation rate is $0.41 \pm 0.16$, suggesting that coagulation between particles decreases the formation rate by about $40 \%$. Hence, coagulation is important for NPF events, since this process decreases the nucleation mode particle number concentration but leads to apparent growth of newly nucleated particles. Moreover, it affects the contribution of NPF to CCN formation. Besides a couple of theoretical analyses (Pierce and Adams, 2007; Kerminen et al., 2004), the quantitative role of coagulation scavenging in $\mathrm{CCN}$ production was investigated in only one field study (Kuang et al., 2009). The ratio of coagulation loss to the formation rate here also suggests that coagulation will decrease the contribution of NPF to CCN formation by about $40 \%$, as the growing nucleation mode particles during NPF events dominate the $\mathrm{CCN}$ number concentrations, accounting for up to $80 \%$ (Wiedensohler et al., 2009).

The sum of intramodal and extramodal coagulation losses estimated with the Moment Method agrees well with the coagulation loss calculated with Eq. (2) and their ratio is $0.98 \pm 0.26$, indicating that the two methods are consistent and comparable. The contributions of intramodal coagulation and extramodal coagulation to the coagulation loss are similar, with a ratio of $0.97 \pm 0.48$. Both preexisting particles and high number concentrations of the nucleation mode particles explain the loss of nucleation mode particles, suppressing the existence of the freshly nucleated particles.

Low condensational sink (corresponding to low particle surface area concentration) is one of the key factors for the NPF occurrence in Beijing (Wu et al., 2007). On one hand, the preexisting particles and nucleation process compete for the precursors such as sulfuric acid. On the other hand, the preexisting particles coagulate with newly formed particles. Therefore, "cleaner" air with less preexisting particles plays
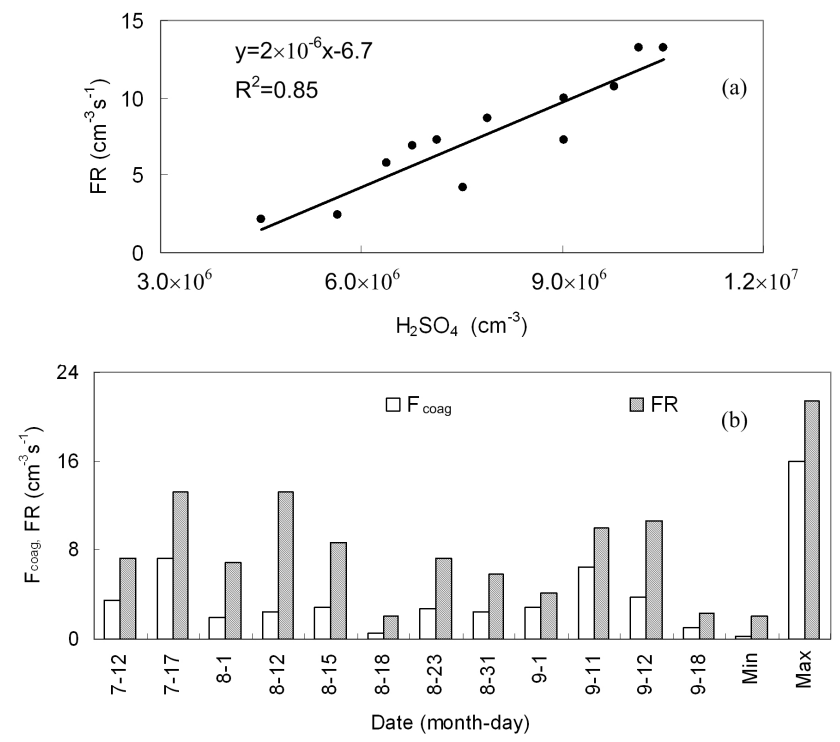

Fig. 2. Relationship of average formation rate (FR) and sulfuric acid concentration (a) and relationship of average coagulation loss $\left(F_{\text {coag }}\right)$ and formation rate (b) during NPF events. Min and Max are the minimum and maximum values from June through August from 2004 to 2008 , respectively.

an important role in the occurrence of NPF events. During the Olympics with the restrictions imposed on industry and traffic, lower levels of particle mass concentrations in the urban area of Beijing were observed, offering an plausible reason for the frequent occurrence of NPF events during this period $(25 \%)$, which was about twice of that before and after the Olympics (about 13\%).

\subsection{Growth of the freshly formed particles}

If the growth of nucleation mode particles is only caused by condensation of sulfuric acid and subsequent neutralization by ammonia to form $\left(\mathrm{NH}_{4}\right)_{2} \mathrm{SO}_{4}$, the calculated growth rates of the nucleation mode particles can not explain the higher apparent growth rates. Similar phenomena were also reported by Stolzenburg et al. (2005): sulfate and ammonium were found to be the only constituents of the $6-10 \mathrm{~nm}$ particles (Smith et al., 2005) but could not explain the particle growth in Atlanta. Another study by Korhonen et al. (2005) also concluded that coagulation growth is non-negligible when considering particle growth. During some of the cases, the particle growth process lasted through the whole afternoon and the particles grew up to about $100 \mathrm{~nm}$, which would impose an important effect on the properties of the $\mathrm{CCN}$ activity.

The apparent growth rates and calculated growth rates caused by the condensation and neutralization of sulfuric acid, intramodal coagulation, and extramodal coagulation on different NPF days during CAREBeijing-2008 are depicted in Fig. 3, showing that these three mechanisms account for 
$79 \pm 31 \%$ of the apparent growth rates, with the contributions of condensation and neutralization of sulfuric acid to be $45 \pm 18 \%$ and coagulation to be $34 \pm 17 \%$. The contributions of intramodal and extramodal coagulation are comparable, accounting for $19 \pm 12 \%$ and $15 \pm 7 \%$, respectively. Sulfate and ammonium account for (52 \pm 14$) \%$ and organic matters take up (36 \pm 13$) \%$ in $40-400 \mathrm{~nm}$ particles during these NPF events with their total contribution being $(89 \pm 8) \%$. It suggests that organic matters may also contribute to the particle growth significantly.

On the basis of the calculated and the apparent growth rate, we classify NPF events into two categories: if the condensation and neutralization of sulfuric acid contributes more than $50 \%$ to the apparent growth rate subtracting the coagulation growth, the particle chemical compositions are mainly sulfate (the sulfur-rich type). In contrast, if the condensation and neutralization of sulfuric acid contributes less than 50\%, other species other than sulfur dominate the growth process (the sulfur-poor type). However, in absolute terms, sulfuric acid concentrations and mass concentrations of sulfate are not necessarily higher during the sulfur-rich events. During the CAREBeijing-2008 campaign, seven events of the sulfurrich type and five events of the sulfur-poor type are identified (Fig. 3a). The condensation and subsequent neutralization of sulfuric acid accounts for $54 \pm 15 \%$ of the apparent growth rates during the sulfuric-rich NPF events and $27 \pm 6 \%$ during the sulfuric-poor ones. While the magnitude of the coagulation growth rate for sulfur-rich and -poor cases are nearly identical; coagulation growth is responsible for $30-50 \%$ and $10-30 \%$ in the measured growth rates for these two cases, respectively. The concentration of sulfate in $40-400 \mathrm{~nm}$ particles is about $30 \%$ higher than organic compounds during the sulfuric-rich NPF events, but is about $20 \%$ lower for the sulfuric-poor cases (Fig. 3c). Hence, we conclude that the unaccountable apparent growth rate (the apparent growth rate subtracting the contribution of the condensation and neutralization of sulfuric acid and coagulation) is mainly contributed by organic compounds. It is also reported that organic compounds rather than sulfate dominate the composition of $10-33 \mathrm{~nm}$ particles during NPF events in Tecamac, Mexico (Smith et al., 2008).

The sulfur-rich NPF events occurred with slightly higher sulfuric acid concentrations $\left((8 \pm 1) \times 10^{6} \mathrm{~cm}^{-3}\right)$ than sulfurpoor type $\left((7 \pm 2) \times 10^{6} \mathrm{~cm}^{-3}\right)$. The sulfur-rich NPF events corresponded to a higher formation rate but lower apparent growth rate than the sulfur-poor type by $17 \%$ and $45 \%$, respectively (Fig. 3b). The average ratio of intramodal coagulation growth to the extramodal coagulation growth during the sulfur-rich NPF events was $1.6 \pm 0.7$, significantly higher than that during the sulfur-poor type $(0.7 \pm 0.3)$. There are several plausible explanations for such a difference. First, higher formation rates of the sulfur-rich NPF events rapidly increase the number concentrations of nucleation mode particles and lower apparent growth rates suppress the transfer of aerosols from the nucleation to the Aitken mode, both
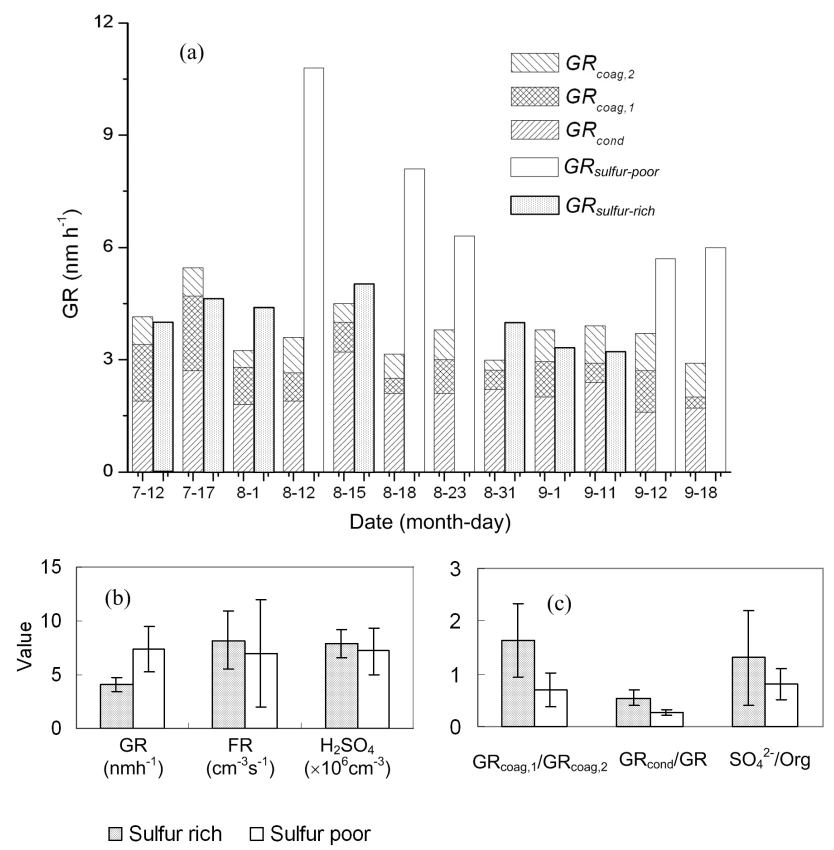

Fig. 3. Apparent growth rates of NPF events and the growth rates caused by the three different mechanisms (a) and comparison of important parameters $(\mathbf{b}, \mathbf{c})$ during the two types of NPF events. GR means growth rate; $\mathrm{GR}_{\text {cond }}$ is the growth rate caused by the condensation and neutralization of sulfuric acid; $\mathrm{GR}_{\text {coag, } 1}$ and $\mathrm{GR}_{\mathrm{coag}, 2}$ are the intramoal coagulation growth rate and extramodal coagulation growth rate, respectively. $\mathrm{SO}_{4}^{2-}$ and Org are mass concentrations of sulfate and organic compounds in $40-400 \mathrm{~nm}$ particles, respectively.

leading to higher number concentrations of nucleation mode particles, promoting the intramodal coagulation process, and causing higher intramodal coagulation growth rates. Alternatively, the condensational sinks of preexisting particles of these two type NPF events were similar, indicating nearly identical surface area concentrations during these two types of NPF events. The surface area concentration reflects one of the key elements of the extramodal coagulation.

Earlier studies on NPF events at rural, remote, or forest sites (e.g. Weber et al., 1997; Birmili et al., 2003; Boy et al., 2005; Smith et al., 2008) show that the contribution of sulfuric acid to the apparent growth of the new particles is typically below $30 \%$. However, such contribution is found to be larger in Beijing especially for the sulfur-rich cases as investigated in this paper and in Atlanta, US, about $60 \%$ on average (Stozenberg et al., 2005). One possible explanation is that the concentration of $\mathrm{SO}_{2}$ is lower in the non-urban area than in the urban area, leading to a lower concentration of $\mathrm{H}_{2} \mathrm{SO}_{4}$ and suppressing the contribution of $\mathrm{H}_{2} \mathrm{SO}_{4}$ to new particle growth. Also, it has been shown by Kiendler-Scharr et al. (2009) that isoprene suppresses the formation but enhances the growth of nucleation mode particles. Hence, abundant isoprene in the non-urban area will contribute more 

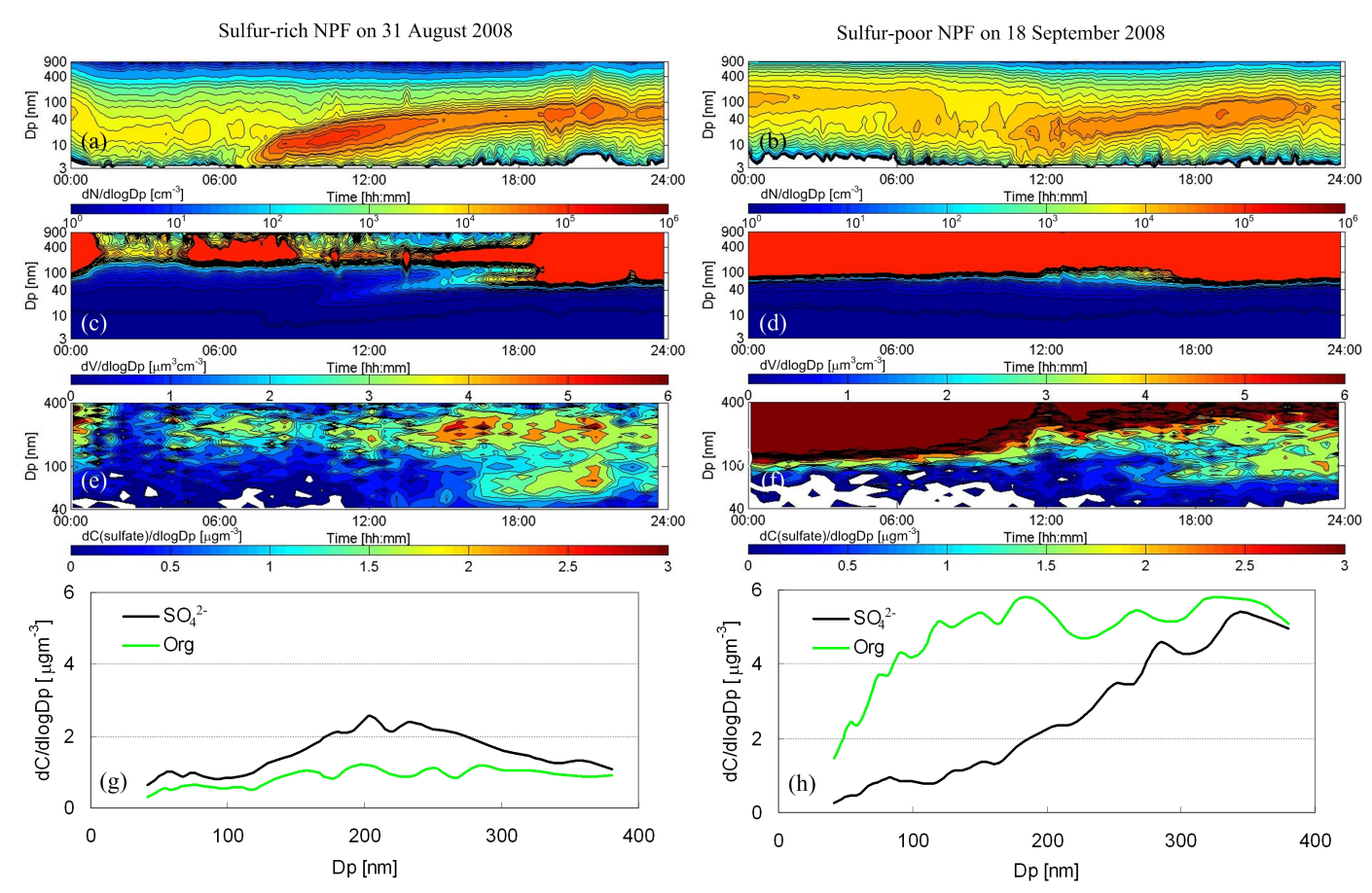

Fig. 4. Particle number size distributions (a, b), particle volume size distributions (c, $\mathbf{d})$, sulfate mass size distributions (e, f), and comparison of average mass size distributions between sulfate and organic compounds from 14:00 to 18:00 LT (g, h) on sulfur-rich and sulfur-poor NPF event days, respectively.

to the growth of the new particles and reduce the fraction of the contribution of $\mathrm{H}_{2} \mathrm{SO}_{4}$. As the environments are complex and different at diverse sites, other factors, such as the concentration of $\mathrm{OH}$ radicals, can also be important and deserve further investigation.

Recent laboratory studies have shown that initial growth of newly nucleated particles $(<4 \mathrm{~nm})$ involves most likely sulfuric acid (Zhang et al., 2009), whereas heterogeneous reactions of certain classes of organics, such as gloyxal, large aldehydes, and amines, lead to growth of particles larger than $4 \mathrm{~nm}$, by forming non-volatile oligomers, polymers and alkylaminium sulfates in the particle phase (Wang et al., 2010).

\subsection{Case study of sulfur-rich and sulfur-poor NPF events}

The NPF event on 31 August is a typical sulfur-rich NPF event. The corresponding average formation rate is $6 \mathrm{~cm}^{-3} \mathrm{~s}^{-1}$ and apparent growth rate is $4 \mathrm{~nm} \mathrm{~h}^{-1}$. An obvious growth of the particle volume size was also observed. When the newly formed particles grow into the size that can be detected by AMS, the growth of sulfate was observed subsequently (Fig. 4), while it is not true for other compositions. Moreover, the average mass size distributions show that the mass concentration of sulfate is significantly higher than that of organic compounds during the event (between 14:00 and 18:00 LT, Fig. 4g). This confirms that sulfate is the most important contributor to the particle growth during this sulfur-rich NPF event: the condensation of sulfuric acid and its subsequent neutralization accounts for about $60 \%$ of the apparent growth rate (cf. Fig. 3a).

The NPF event on 18 September with an average formation rate of $2 \mathrm{~cm}^{-3} \mathrm{~s}^{-1}$ and an apparent growth rate of $6 \mathrm{~nm} \mathrm{~h}^{-1}$ belongs to the sulfur-poor type (Fig. $4 \mathrm{a}$ ). In contrast to the case on 31 August, the mass concentration of organic compounds is significantly higher than that of sulfate during the event, as shown in Fig. 4h. It means that the contribution of organic compounds to particle growth is larger than that of sulfate.

At the start of the NPF event on 18 September, the nucleation mode particles were observed to grow from above $10 \mathrm{~nm}$ (geometric mean diameter), in contrast to 31 August from sub-10 nm. Transport of particles from the surrounding areas to the PKU site and fast growth of small particles during the start of this NPF event on 18 September are possible reasons, although further investigation is needed to verify this observation.

\section{Conclusions}

Twelve regional NPF events were discerned and analyzed based on the measured aerosols and sulfuric acid with an aerosol dynamic model during the CAREBeijing-2008 campaign. Sulfuric acid plays a dominant role both in the new particle formation and subsequent growth processes. It has a 
linear correlation with the average formation rates $\left(R^{2}=0.85\right)$ during the NPF events; its condensation and subsequent neutralization by ammonia contributes $45 \pm 18 \%$ to the apparent growth rate on average. Coagulation plays a significant role in reducing the number concentration of nucleation mode particles and contributing to the apparent growth of the freshly formed particles. On average, the ratio of coagulation loss to the formation rate is $0.41 \pm 0.16$ and coagulation contributes $34 \pm 17 \%$ to the apparent growth rate. The condensation and neutralization of sulfuric acid together with coagulation accounts for $80-100 \%$ of the apparent particle growth rate among seven sulfur-rich NPF events, during which sulfate is the major composition of the ultrafine particles. While for the five sulfur-poor NPF events, the concentrations of sulfate in ultrafine particles is significantly lower than those of organic compounds, that is to say organic compounds are the major composition. Organic compounds are responsible for the particle growth, besides condensation and neutralization of sulfuric acid and coagulation, especially during the sulfurpoor NPF events.

During some cases the growth processes last through the whole afternoon, causing the particles grow up to $100 \mathrm{~nm}$, which will impose significant effect on CCN. However, coagulation reduces the efficacy of $\mathrm{CCN}$ formation contributed by NPF because coagulation decreases the number concentration of nucleation mode particles significantly. In addition, the different shares of sulfate and organic compounds in these particles will lead to different hygroscopic growth property and $\mathrm{CCN}$ activity.

It is also very interesting and important to investigate the role of organic compounds such as pinic acid and ketopinic acid in the early stage of NPF events. Further research is necessary based on the measurement of the potential organic precursors and the chemical compositions in the very small particles, for instance 3-10 nm.

Acknowledgements. This work as part of the Campaign of Atmospheric Research in Beijing and surrounding areas in 2008 is supported by Beijing Council of Science and Technology. It is also supported by the National Natural Science Foundation of China (20637020, 20977001), European Integrated project on Aerosol Cloud Climate and Air Quality interactions (EUCAARI, No. 036833-2) and the Foundation of State Key Joint Laboratory of Environmental Simulation and Pollution Control (08Z01ESPCP).

Edited by: M. Gauss

\section{References}

Arnold, F. and Fabian, R.: 1st measurements of gas-phase sulfuricacid in the stratosphere, Nature, 283, 55-57, 1980.

Barsanti, K. C., McMurry, P. H., and Smith, J. N.: The potential contribution of organic salts to new particle growth, Atmos. Chem. Phys., 9, 2949-2957, doi:10.5194/acp-9-2949-2009, 2009.
Birmili, W., Berresheim, H., Plass-Dülmer, C., Elste, T., Gilge, S., Wiedensohler, A., and Uhrner, U.: The Hohenpeissenberg aerosol formation experiment (HAFEX): a longterm study including size-resolved aerosol, $\mathrm{H} 2 \mathrm{SO} 4, \mathrm{OH}$, and monoterpenes measurements, Atmos. Chem. Phys., 3, 361-376, doi:10.5194/acp-3-361-2003, 2003.

Biskos, G., Buseck, P. R., and Martin, S. T.: Hygroscopic growth of nucleation-mode acidic sulfate particles, Aerosol Sci., 40, 338347, 2009.

Boy, M., Kulmala, M., Ruuskanen, T. M., Pihlatie, M., Reissell, A., Aalto, P. P., Keronen, P., Dal Maso, M., Hellen, H., Hakola, H., Jansson, R., Hanke, M., and Arnold, F.: Sulphuric acid closure and contribution to nucleation mode particle growth, Atmos. Chem. Phys., 5, 863-878, doi:10.5194/acp-5-863-2005, 2005.

Eisele, F. L. and Tanner, D. J.: Measurement of the gas-phase concentration of $\mathrm{H}_{2} \mathrm{SO}_{4}$ and methane sulfonic-acid and estimates of $\mathrm{H}_{2} \mathrm{SO}_{4}$ production and loss in the atmosphere, J. Geophys. Res., 98(D5), 9001-9010, 1993.

Fortner, E. C., Zhao, J., and Zhang, R. Y.: Development of ion drift-chemical ionization mass spectrometry, Anal. Chem., 76, 5436-5440, 2004.

Fuchs, N. A.: The Mechanics of Aerosols, Elsevier, New York, 1964.

Huang, X.-F., He, L.-Y., Hu, M., Canagaratna, M. R., Sun, Y., Zhang, Q., Zhu, T., Xue, L., Zeng, L.-W., Liu, X.-G., Zhang, Y.-H., Jayne, J. T., Ng, N. L., and Worsnop, D. R.: Highly time-resolved chemical characterization of atmospheric submicron particles during 2008 Beijing Olympic Games using an Aerodyne High-Resolution Aerosol Mass Spectrometer, Atmos. Chem. Phys. Discuss., 10, 13219-13251, doi:10.5194/acpd-1013219-2010, 2010.

Heintzenberg, J.: Properties of the log-normal particle size distribution, Aerosol Sci. Technol., 21, 46-48, 1994.

Kerminen, V.-M., Kulmala, M.: Analytical formulae connecting the "real" and the "apparent" nucleation rate and the nuclei number concentration for atmospheric nucleation events, J. Aerosol Sci., 33, 609-622, 2002.

Kerminen, V.-M., Lehtinen, K. J., Anttila, T., and Kulmala M.: Dynamics of atmospheric nucleation mode particles: a timescale analysis, Tellus, 56B, 135-146, 2004.

Kiendler-Scharr, A., Wildt, J., Dal Maso, M., et al.: New particle formation in forests inhibited by isoprene emissions, Nature, 461, 381-384, 2009.

Korhonen, H., Kerminen,V. M., and Kulmala, M.: Development and application of a new analytical method to estimate the condensable vapor concentration in the atmosphere, J. Geophys Res., 110, D05201, doi:10.1029/2004JD005458, 2005.

Kuang, C., McMurry, P. H., and McCormick, A. V.: Determination of cloud condensation nuclei production from measured new particle formation events, Geophys. Res. Lett., 36, L09822, doi:10.1029/2009GL037584, 2009.

Kulmala, M., Vehkamaki, H., Petajda, T., Dal Maso, M., Lauri, A., Kerminen, V. M. Birmili, W., and McMurry, P. H.: Formation and growth rates of ultrafine atmospheric particles: a review of observations, Aerosol Sci., 35, 143-176, 2004.

Kulmala, M. and Kerminen, V. M.: On the formation and growth of atmospheric nanoparticles, Atmos. Res., 90, 132-150, 2008.

Lin, P., Hu, M., Wu, Z., Niu, Y., and Zhu, T.: Marine aerosol size distributions in the springtime over China adjacent seas, Atmos. 
Environ., 41, 6784-6796, 2007.

Liu, S., Hu, M., Wu, Z. J., Wehner, B., Wiedensohler, A., and Cheng, Y. F.: Aerosol number size distribution and new particle formation at a rural/coastal site in Pearl River Delta (PRD) of China, Atmos. Environ., 42, 6275-6283, 2008.

Marti, J. J., Jefferson, A., Cai, X. P., et al.: $\mathrm{H}_{2} \mathrm{SO}_{4}$ vapor pressure of sulfuric acid and ammonium sulfate solutions, J. Geophys. Res., 102(D3), 3725-3735, 1997.

McMurry, P. H., Fink, M., Sakurai, H., et al.: A criterion for new particle formation in the sulfur-rich Atlanta atmosphere, J. Geophys. Res., 110, D22S02, doi:10.1029/2005JD005901, 2005.

O’Dowd, C., Aalto, P., Hämeri, K., Kulmala, M., and Hoffmann, T.: Atmospheric particles from organic vapours, Nature, 416, 497498, 2002.

Pierce, J. R. and Adams, P. J.: Efficiency of cloud condensation nuclei formation from ultrafine particles, Atmos. Chem. Phys., 7, 1367-1379, doi:10.5194/acp-7-1367-2007, 2007.

Smith, J. N., Moore, K. F., Eisele, F. L., et al.: Chemical composition of atmospheric nano-particles during nucleation events in Atlanta, J. Geophys. Res., 110, D22S03, doi:10.1029/2005JD00, 2005.

Smith, J. N., Dunn, M. J., VanReken, T. M., et al.: Chemical composition of atmospheric nanoparticles formed from nucleation in Tecamac, Mexico: Evidence for an important role for organic species in nanoparticle growth, Geophys. Res. Lett., 35, L04808, doi:10.1029/2007GL032523, 2008.

Stolzenburg, M. R., McMurry, P. H., Sakurai, H., et al.: Growth rates of freshly nucleated atmospheric particles in Atlanta, J. Geophys. Res., 110, D22S05, doi:10.1029/2005JD005935, 2005.

Wang, L., Khalizov, A. F., Zheng, J., et al.: Atmospheric nanoparticles formed from heterogeneous reactions of organics, Nature Geosci., 3, 238-242, doi:10.1038/NGEO778, 2010.
Weber, R. J., Marti, J. J., McMurry, P. H., et al.: Measurements of new particle formation and ultrafine partile growth rates at a clean continental site, J. Geophys. Res., 102(D4), 4375-4385, 1997.

Wiedensohler, A., Cheng, Y. F., Nowak, A., et al.: Rapid aerosol particle growth and increase of cloud condensation nucleus activity, J. Geophys. Res., 114, D00G08 doi:10.1029/2008JD010923, 2009.

Willeke, K. and Baron, P. A.: Aerosol Measurement Principles, Techniques, and Applications, Van Nostrand Reinhold, Hoboken, NJ, 1993.

Wu, Z., Hu, M., Liu, S., et al.: New particle formation in Beijing, China: Statistical analysis of a 1-year data set, J. Geophys. Res., 112, D09209, doi:10.1029/2006JD007406, 2007.

Yue, D., Hu, M., Wu, Z., et al.: Characteristics of aerosol size distributions and new particle formation in the summer of Beijing, J. Geophys. Res., 114, D00G12, doi:10.1029/2008JD010894, 2009.

Zhang, R., Suh, I., Zhao, J., et al.: Atmospheric new particle formation enhanced by organic acids, Science, 304(5676), 1487-1490, 2004.

Zhang, R., Wang, L., Khalizov, A. F., et al.: Formation of nanoparticles of blue haze enhanced by anthropogenic pollution, P. Natl. Acad. Sci. USA, 106, 17650-17654, doi:10.1073/pnas.0910125106, 2009.

Zheng, J., Khalizov, A., Wang, L., et al.: Implementation of atmospheric pressure ion-drift tube in chemical ionization mass spectrometry for detection of trace gas species, in preparation, 2010a.

Zheng, J., Yue, D. L., Zhang, R. Y., et al.: First gaseous sulfuric acid measurement in a Chinese mega-city: study of sulfate aerosol formation and homogeneous nucleation rate during the CAREBeijing-2008 campaign, to be submitted to Atmos. Chem. Phys., 2010b. 